Article

\title{
The Relation between Environmental Management Systems and Environmental and Financial Performance in Emerging Economies
}

\author{
Cosmina L. Voinea *(D), Bas-Jan Hoogenberg, Cosmin Fratostiteanu and Hammad Bin Azam Hashmi \\ Faculty of Management, Open University of the Netherlands, 6419 AT Heerlen, The Netherlands; \\ bas-jan.hoogenberg@protonmail.com (B.-J.H.); cosminfratostiteanu@yahoo.com (C.F.); \\ hammad.shah046@gmail.com (H.B.A.H.) \\ * Correspondence: cosmina.voinea@ou.nl
}

Received: 13 May 2020; Accepted: 2 June 2020; Published: 1 July 2020

check for updates

\begin{abstract}
This study pursues to clarify the effect of environmental management systems (EMS) comprehensiveness on environmental performance and financial performance using an extensive quantitative dataset obtained in Brazil over an eight-year period. It is recognized that the implementation of environmental management differs per company varying in how many environmental practices are adopted and hence how comprehensive the EMS is. The relationship between EMS comprehensiveness, environmental performance, and financial performance proves to be complex. First of all, the overall negative effect of environmental performance on financial performance may indicate that the resources needed to realize an improved environmental performance do not outweigh the cost reductions resulting from eco-efficiency or improved reputation. The effect of EMS comprehensiveness on financial performance is in line with that, indicating that an above average EMS comprehensiveness results in lower financial performance, which may correspond to high environmental management- and overhead costs. Across sectors, the companies operating in sector industries have high quality EMS comprehensiveness, while the companies in agriculture, commerce, and services exhibit a lower EMS.
\end{abstract}

Keywords: environmental management systems; environmental performance; financial performance; emerging economies; Brasil

\section{Introduction}

The advanced industrialisation of society has resulted in a large metamorphosis of the emerging economies. Though living standards may have increased, another effect is without a doubt a strong impact on the environment. Greenhouse gas emissions, the use of natural resources, and the disposal of waste and toxic substances are all thought to have a strong effect on climate change. In addition, a growing population and expectations for further improvements in welfare may result in an even higher demand for the world's resources. A growing awareness of this unsustainable state of exponential growth and excessive consumption of resources led to a more conscious policy regarding the environmental footprint. The resulting effect is stronger focus on the environment and sustainable resource usage, by governments, citizens, and industry [1].

Growing concerns over this influence on the environment have led to increased awareness on the effect of companies and industry on the environment. Pressures, originating from for instance customers, governments, NGOs, or the industry, lead to a focus within companies on environmental performance. Since much of the resource consumption is related to goods and services that need to be manufactured, used, maintained and disposed of, one of the logical political focus areas on 
reducing environmental impact is therefore on companies. Here, the focus is both on reducing the constant resource usage as well as preventing accidents that can have an incidental yet excessive environmental impact.

One policy instrument to affect environmental performance is by defining rules and regulations. Such a hierarchical approach aims at setting broad and minimal requirements, thereby forcing companies under that jurisdiction to comply with those 'hard' rules. In sharp contrast with such approaches, new environmental policy instruments focus more on defining procedures that are required. This follows a broader approach on regulating and similar strategies that have been implemented in for instance safety regulation in other industries. Such 'soft' policy instruments largely rely on voluntary implementation and action, learning processes, and procedural change instead of direct control exerted by a regulatory body. This allows companies to be flexible in their implementation and execution of such procedures, which is thought to result in a more dynamic, effective, and less resource-intensive way to improve environmental performance. However, critics doubt the superiority of such policy instruments over 'old-fashioned' rule-setting and claim the actual environmental improvement may be less than expected. The effect of such systems is not as directly observable due to the voluntary nature [2].

Environmental Management Systems (EMS) are the most evident implementation of such 'soft' instruments. The International Standardization Organization (ISO) has created ISO 14001 as a framework and guideline to implement an EMS. As of 2014, more than 300,000 companies have implemented the standard [3]; almost doubling the number of companies compared to 2006 [4]. EMS are common procedural tools to monitor, measure, plan, and make choices regarding environmental performance. Rather than having a direct effect on environmental performance, the effects of such procedures are thought to be indirect. In the first place, it should aid in altering the institutionalized perception that pollution is a logical resultant from (profitable) economic activity. In effect, the realization that environmentally beneficial actions do not necessarily result in excessive costs and thereby promoting such actions [2]. However, how many of such environmentally beneficial actions are required or how to balance environmental costs with financial costs is unknown. Though the ISO-regulations describe a systematic approach to managing the impact on the environment, environmental targets remain undefined and environmental reporting is not required.

As described above, there is thus doubt about the actual effect of an EMS on the environmental performance. There are two important aspects that hinder agreement on this topic. In the first place; no EMS is the same. The voluntary and flexible nature results in company-specific procedure implementations. For instance, responsibilities may lie in different departments, procedures may focus on different topics (i.e., water usage reduction, communication of environmental performance, life-cycle management) or there could be different procedures for (self) auditing. In summary; the comprehensiveness of the EMS varies between companies.

Secondly, quantitative and uniform methods for the assessment of a firm's environmental performance do not exist or are not agreed upon [5,6]. Due to differences in policies or focus point, companies may report different performance indicators. Other companies may not report at all. The result is that studies range from quantitative measurements of environmental performance [7] to qualitative studies where an interviewee is asked about their perception of the environmental performance $[8,9]$.

Previous research on the effect of the EMS on environmental performance has yielded conclusions ranging from no significant effect to a positive influence of the EMS on the environmental performance [3,4]. The inconclusive results on this relation present an opportunity for further research.

Often, environmental performance is claimed to hinder financial performance. In the first place, the costs and resources involved with implementing the ISO 14001 are an often cited drawback [3], let alone the perceived costs of environmental good-doing [2]. However, some companies have managed to align environmental- with financial performance and realize both targets simultaneously [8]. Studies have found a positive relation between EMS and financial performance [10] (or disprove a 
negative relation [11] as well as correlations between environmental- and financial performance [12]. The minor disagreement seems present on the effect on financial performance, yet it is not uniform whether the EMS or environmental performance is an indicator of increased financial performance.

Though EMS has been implemented by a large variety of firms and organizations, research has pursued to identify determinants of its implementation. More specifically, certain determinants may result in a more comprehensive EMS that has for instance strong institutionalized procedures for responsibilities, training, and audits. One determinant may be company size $[8,13]$. The costs involved with implementation are a significant drawback [3] and may be easier to cover for larger companies. Also, economies of scale may play a role, where larger companies may be in a better position to reap the benefits of the improved performance compared to a smaller company [14]. On the other hand, there may be a relation between the degree of globalization and the EMS comprehensiveness as multinational corporations (MNCs) operate in multiple legal and social areas and have to design their environmental practices accordingly so that they can meet all the required regulations $[15,16]$. Therefore, a global approach to the EMS would result in procedures that need to address the most stringent combination of national requirements on environmental practice [16]. Keeping these determinants in mind, the objective is to investigate the relationship between the comprehensiveness of the environmental management systems, the environmental performance, and the financial performance of MNCs in emerging economies.

There is strong disagreement and contradictory arguments about the relations between EMS, environmental performance and financial performance, even though a large number of research papers on these topics can be found [17].

Furthermore, existing literature provides confusing and opposing evidence regarding environmental management systems determinants for MNCs. Some studies claim that company size is the most determinant of the quality of environmental management systems [8] other studies argue for the degree of globalization as most relevant for environmental management systems [16].

Policymakers should valorise the outcome of our study to add to the debate around the MNCs relocating activities to countries with less strict environmental requirements [15]. Considering such effects, the political discussion on the balance between (international) competitiveness of a country's economy (financial performance) and reducing the environmental footprint of that country (environmental performance) may be more in favour of stricter regulations if those indeed go hand in hand [18].

Furthermore, with globalization as a key indicator for EMS comprehensiveness, this provides tools for national or regional policy makers to influence the environmental performance across the border with more global effectiveness. However, if a firm's size is a key indicator this may steer policymakers towards size-dependent policies. Here, there may be a focus on exploiting economies of scale for the larger companies, while not hindering new entrants with too high entry barriers [14].

Managers or consultants in the industry can use the research outcome to design the company's EMS. Certain EMS characteristics may aid in promoting improved environmental performance and/or financial performance. With such characteristics in mind, the cost of implementing the EMS may have an increased ROI, be it through financial or environmental gain mechanisms. If the outcome is that the determining EMS aspects are the same for both financial- and environmental performance, the ROI increase is even stronger. Such an outcome should provide firms with the confidence to adopt EMS and reap the financial benefits while reducing their environmental footprint.

Further, the study is structured as follows. First, previous literature on the EMS is elaborated along with predictors and outcomes of EMS to identify the research gap. Second, the methodology is defined which covers delineation of the research context, operationalization of variables, study sample, and data collection. Third, results are reported which include descriptive findings and hypotheses testing mainly. Forth, discussion of the main findings is done. Lastly, the study is concluded with answers to main research questions, literature reflection, and future research directions. 


\section{Literature Overview}

\subsection{Environmental Management Systems}

The Environmental Management System (EMS) is 'the portion of the overall management system which includes organizational structure, planning activities, responsibilities, practices, procedures, processes and resources for implementing, achieving, reviewing, and maintaining the environmental policy'. It thus denotes a rather broad range of disciplines and activities intending to have a policy on the environment [19] with this definition, the goal of the EMS is to provide the characteristics of the management system to address those aspects effectively. Here, effectively refers to both an efficient implementation, and, to aid in realizing environmental performance $[4,20]$. Many large multinationals have now certified their EMS under the ISO 14001 [20] and the number of certifications has doubled from 2006 to 2014 [3,4].

A core aspect of the EMS as described in the ISO is the 'plan-do-check-act'-cycle (PDCA) as a tool to systematically address and actively manage environmental issues. The EMS should address all those steps in the cycle and should thus provide the required procedures, responsibilities, and resources to go from a recognition of the problem to controlling and monitoring it [21].

It is important to stress that the implementation of an EMS (or ISO 14001 certification) does not ensure that a firm is compliant with the minimal legal environmental requirements or that it is continuously improving the environmental performance [20]. Some critics go as far as labelling an EMS implementation as a superficial tool to improve stakeholder perception without an attempt to improve environmental efficiency [22].

The perceived effect of an EMS has not been extensively studied, yet commonly reported effects are; improvement of stakeholder relationships, such as a greener customer perception $[3,23]$ or preventing the introduction of stricter regulations [24], and an improvement of performance, be it financial and/or environmental [25].

In addition, the ISO 14001 for an EMS, the 14000 series contains more standards on environmental management. The standards in addition to 14001 can be seen as supporting standards that focus on more specific topics of environmental management ("ISO 14000 family - environmental management," n.d.). ISO are meant to help the organization to organize proper management, Eco-Management and Audit Scheme (EMAS) Regulation (Reg 761/01 EC) is EU scheme implemented by the European Commission and it is for the implementation of an Environmental Management System (EMS) by any organization.

The EMS can be regarded as an incentive-based policy instrument [20,26], the opposite of command-and-control where strict qualitative and quantitative limits on emissions are imposed [27]. EMS includes: Environmental auditing; Evaluation of environmental performance; Environmental labelling; Analysis of lifecycle of product and service; Environmental communication.

The instruments are voluntary in nature and based on learning processes and procedural change. Such instruments have gained popularity whereas previous hierarchical instruments were thought not to provide dynamic incentives to improve environmental performance [28]. Also, such flexible instruments would be more cost-effective, partly due to the self-regulatory nature rather than enforcement by public authorities [2]. It has been observed that such incentive-based instruments (i.e., with fewer 'hard' demands) have a higher participation rate [29]. This can be credited to the actual behaviour of employees and managers in a firm which is not so much steered by facts and rules, but by their (subjective) perception of facts and rules. The resulting effect is ignorance about the status quo due to an institutionalized perception of a negative relation between environmental good-doing and economic gains [2]. Such 'framing' obviously reduces the will to change to environmentally beneficial practices.

The procedural goal in the EMS is to reduce the subjective component in the interpretation, by providing learning and a structural approach to sense making [2]. Here, one must assume that the behaviour of the firm is a resultant of the behaviour of all, or some key, employees. Following the theory 
of planned behaviour, the behaviour results from intention. The stronger the intention, the higher the effort, and the more likely that you engage in the intended behaviour. Intention results from attitudes, subjective norms, and perceived behavioural control [30]. Learning and insight can affect the beliefs that form the attitude. The presence of an EMS and recurring managerial attention to the environment could alter how employees believe their environmental behaviour is judged by others and thus affect their subjective norms. The procedures in the EMS should provide the tools to alter the behaviour and thus affect an employee's perceived possibility to control environmental performance.

\subsection{EMS Comprehensiveness}

It has been observed that the realisation of environmental management is done differently by companies. A commonly used instrument to differentiate between how actively companies focus on environmental management is by looking at comprehensiveness (meaning completeness or all-inclusiveness [19] Definitions used include for example:

Arimura, Hibiki and Katayame [27] used "Comprehensiveness was measured as the number of environmental practices adopted by the facility, implementation of a certified EMS, specifically ISO 14001, and publication of environmental reports".

Darnall [19] argue that "facilities that implement more of these environmental practices as part of their EMS may be regarded as having a more comprehensive EMS than facilities with fewer of these environmental practices".

Phan and Baird [9] operationalized EMS comprehensiveness "with respect to the intensity of use of nine environmental practices identified as important components of an EMS".

Thus, the environmental intensity of a company is often measured by EMS comprehensiveness, which is operationalized by looking at the number of and/or frequency of environmental practices that a company employs. These include the abovementioned ISO 14000 series standards, for example for environmental management, environmental reporting, or product life-cycle management [28].

\subsection{Determinants of EMS Comprehensiveness}

The comprehensiveness of a firm's EMS may be affected by the characteristics of the firm. The implementation of an EMS is perceived as a complex undertaking that requires the right expertise and sufficient resources [8]. It can, therefore, be argued that the resources the firm can dedicate to the implementation and the know-how, either through experience or acquired, can be of influence to the environmental management performance. Multiple determinants may be of influence and will be discussed hereafter.

\subsubsection{Firm Resources}

\section{Tangible resources}

It has been found that improved environmental performance is associated with larger and innovative factories where quality- and manufacturing improvement are actively managed. On average, the individual sites had more than 250 employees, had more staff dedicated to environmental practices, and are likely to be part of a larger company [8,13]. Larger companies are more likely to have the slack resources required to address environmental management [16,31]. Here, economies of scale thus play a role and large enterprises may be in a better position to reap the economic benefits of an improved environmental performance than smaller entities [14].

In addition to economic arguments about why larger companies may implement more complete and comprehensive EMS, their size also increases visibility. Size becomes a liability, where larger companies are expected to do more on environment management [16].

In quantity, many more small- $(<50)$ and medium $(<249)$ enterprises exist, but only a few have implemented a (formal) EMS. Estimates indicate that those SMEs could contribute to as much as $70 \%$ of all pollution. In addition to insufficient (human-) resources to successfully implement and execute an EMS, unsupportive company culture towards environmental performance, scepticism towards 
benefits of an EMS, and absence of customer pressure has resulted in a minimal implementation rate at SMEs [32].

Hypothesis 1a (H1a). Firm size positively relates to the comprehensiveness of the EMS, thus the larger the firm the more comprehensive its EMS.

\section{Intangible resources:}

Time devoted to having a (formal) EMS may result in a more comprehensive EMS as the firm gains more experience with environmental management. Over time such management systems may grow and a maturated EMS can allow the firm to make proper use of the tools. However, it has been found that the age of (and experience with) the EMS has a minor effect on performance, though it may affect the EMS comprehensiveness. A possible explanation for this is that over-time all easy environmental improvements have already been implemented (the 'low-hanging fruit') and the further performance improvements are of a more difficult and resource intensive nature [33]. Therefore:

Hypothesis $\mathbf{1 b} \mathbf{( H 1 b )}$. Firm experience is positively related to the EMS comprehensiveness and therefore older firms have a higher environmental management performance.

Hypothesis 1c (H1c). EMS age is positively related to the EMS comprehensiveness and thus firms who have implemented an EMS for a longer period already have a higher environmental management performance.

\subsubsection{Globalization}

Multiple sources state a relation between the level of globalization and the environmental performance of MNCs. More specifically, as suggested by Sharfman et al., (1) the greater the degree of globalization, (2) the more diversification across industries, (3) the more diversification across countries, (4) the more centralized the firm and (5) the more standardized the product, the higher the firm's level of environmental performance. Similar to size, a global presence also increases visibility. In order to meet or exceed legitimacy to operate, the expectations are higher when firms operate globally rather than local [16] as the global firms face a plurality of legal requirements on environmental performance. To conform these requirements, global companies are required to opt for a uniform and global policy on environmental management. Consequently, the resulting EMS will be of a higher level [15]. In contrast, firms may take globalization as an opportunity to transfer environmental technologies, procedures, and processes from stricter to less strict countries. Yet some argue that globalization may lead to a transfer of polluting practices to countries with lower environmental requirements, often referred to as 'pollution haven'. However, empirical evidence of such practices is weak [34] therefore we formulate the following hypothesis:

Hypothesis 1d (H1d). The degree of globalization positively influences the comprehensiveness of EMS and therefore the higher the degree of globalization of the firm, the more comprehensive its EMS.

\subsection{Environmental Performance}

Studies have used definitions ranging from absolute quantities to the relative results of changes and focus on the outcome of the management of activities, the activities itself or the final (financial) result of activities. Others refer to the definition provided in the ISO 14031/14001, namely '(measurable) results of an organization's management of its environmental impact'. Thus, on the one hand, the focus is the (extent of) activities done for environmental management, and on the other hand the results from those activities [35,36]. For this study, the ISO definition shall be leading. Here, arguably, the extent of activities for environmental management is corresponding to the comprehensiveness of the EMS as discussed before. Hence the remaining definition is the operational effect on environmental performance. This operational performance should be measured relatively; how is the usage changing 
over time (due to environmental management)? The reason for this is that activities, product requirements, and situations that organizations face will never be comparable and in effect comparing absolute usage would be non-valid [2]. The operational effects can be grouped into inputs and outputs. Inputs focus on the changes in resources that enter the firm, such as water, paper, gas, and electricity. The outputs focus on what leaves the firm, such as solid waste, carbon emissions, NOx emissions, and wastewater [37,38].

EMS and environmental performance

Many studies have explored the relationship between EMS and environmental performance. The results vary from negative- to no- or positive correlations. Yet, all those studies are difficult to compare, since they may employ different measurement parameters and focus on different industries. In order to construct a hypothesis, it is thus key to take into account the specific research goal and definitions of the source. Systematic reviews, such as those created by Boiral et al. and Hertin et al. [2,3]. can aid in providing an overview of the outcome as well as the used definitions per publication $[2,3]$.

Iraldo and Frey (2009) [26] show the positive impact of a well-designed environmental management system on environmental performance. When looking at quantitative and specific environmental indicators, such as waste and energy consumption, the large majority of studies have found a significant improvement with the implementation of ISO 14001, compared to firms without the ISO. When these indicators are defined in a more general fashion (and in effect the data is less quantitative), the significance becomes less pronounced $[2,3,8]$. Looking at the effect of an EMS as a general indicator, the significance is also less pronounced. However, when taking EMS comprehensiveness into account, the effect of the EMS on environmental performance becomes significant. Here comprehensiveness indicators are environmental management practices, such as employee training, environmental policies, internal audits [39], implications of Eco-Management and Audit Scheme (EMAS) regulation [26]. More specifically, while certification of the EMS may help increase performance [26], the number of optional standards from the ISO implemented help to organize proper management, in case of EMS environmental management [33]. This may indicate that the implementation of a comprehensive EMS, and thus the quality of the EMS, rather than the implementation of an EMS as a binary indicator, may be key to the realization of environmental improvements $[2,9,26]$. Therefore, we formulate the following:

Hypothesis 2 (H2). The more comprehensive the EMS is than the greater the improvements in environmental operational performance.

\subsection{EMS, Environmental Performance and Financial Performance}

Environmental performance was long thought to be opposing financial performance, yet some firms seem to realize both simultaneously. The EMS are tools that may promote innovation due to the nature of the EMS and the firms where financial and environmental performance was improved were usually those that were most innovative [8]. It is thought that EMS is the learning tool that provides the organisation with critical information [33]. Similarly, those criticizing environmental regulations and EMS for their negative effect on economic competitiveness, are often those not considering innovation as a key source for performance improvements [40].

Financial effects due to environmental management can be broad. Ranging from direct effects, such as cost reductions due to decreased resource usage, and indirect effects, which include marketing advantages and an improved reputation. EMS can play an important role in the reputation and therefore affect the customer's loyalty and satisfaction [41]. Here, a clear indirect effect on financial performance has been observed [10].

On a manufacturing plant-level, the introduction of greener technologies leads to improved manufacturing performance and environmental performance as well. Here, both the perceived and objectively measured financial performance improved [13]. The rationale behind this is a reduction of resource input and the waste outcome has an effect on the environmental- and financial performance [33]. For high-adopters, the effect of an EMS was much stronger on both cost-savings and emission reduction 
compared to non-adopters [8], and the more comprehensive the EMS, the higher the financial gains [19]. However, the effect of the EMS may not always be both positive on environmental- and financial performance. For example, the EMS may organize environmental duties more efficiently or identify cheaper options for waste disposal. This would positively affect financial performance, without a change in environmental performance [2]. From this overview, it could be claimed the effects of the EMS on financial performance are perceived through two possible paths. First, the EMS can have a direct effect on the firms' reputation and therefore on the financial performance. Secondly, by affecting environmental performance the EMS improves eco-efficiency and thereby financial performance. Therefore, we formulate the following:

Hypothesis 3a (H3a). The more comprehensive the EMS, the larger the improvements in financial performance.

Hypothesis $3 \mathbf{b}(\mathbf{H} 3 \mathbf{b})$. The larger the improvements in environmental performance, the larger the improvements in financial performance.

\section{Methodology}

\subsection{Research Context: Environmental Research, Management and Performance in Brazil}

Compared to countries with a comparable GDP, Brazil has a relatively low energy usage per capita and a strong environmental regulatory regime [42]. Of all BRICS countries, China, India, and Brazil have the most sustainable focus on development. Possibly due to that, sufficient research on environmental management can be found for those countries, as opposed to Russia and South-Africa [43].

As of 2007, 40\% of the companies in Brazil had implemented a certified EMS [44]. The primary incentive and outcome of EMS is eco-efficiency. Here, on the proposed scale from reactive to preventive to proactive, Brazil can be considered preventive [45]. This means that companies are doing more than the minimum required by legislation (which is considered simply 'reactive') and are looking for options to reduce resource usage, hence eco-efficiency. They cannot be regarded as proactive, which would include active innovations towards more environmentally friendly processes and products with environmental-friendliness as the prime motivator [46].

A self-reflective survey study yielded a perceived positive effect on environmental performance (i.e., energy and waste reduction as well as incident reduction), and a positive effect on business, such as being more attractive to investors $[44,46]$. This was, however, not a quantitative study. Quantitative analysis may be performed by using disclosed information on company websites. The completeness of such information varies a lot per sector, with mainly mining, paper, and energy companies disclosing conclusive information [47].

\subsection{Operationalization of Variables}

Firm size is measured by a number of employees. The value has been normalized using the common logarithm. Normalization using the common logarithm creates a more normalized distribution and a more comprehensible format than the natural logarithm. By logical reasoning, it can also be argued that this is a more suitable data format. The difference between a small and large company is notlinear, but is a logarithmic difference (i.e., ten- or hundredfold higher number of employees).

Firm experience in (host) country refers to general operating experience measured in years in Brazil. Thus, for international countries, it is measured starting from the year the company started its operations in Brazil. The value was then recalculated to years of experience by subtracting the questionnaire date from the year the operations started. The value was normalized on the logarithmic scale.

EMS age is the second measure of experience, indicating how long the environmental management system has been implemented. In the questionnaire, this has been categorically asked to respondents, for instance, 2-5 years or more than 10 years. Hence, the data is included as categorical and ordinal. 
Globalization can make use of a region of origin (categorical). Region of origin can be a valuable indicator since it indicates the cultural roots of a company. The literature investigation suggests that the region of origin may be a valuable measure, because the location of the headquarter of the company may highly affect the 'blueprint' of the EMS. This can be in either a positive way, where stricter regulations are universally adopted [16], or a negative way where a country with different environmental requirements could be exploited as 'pollution haven' [34]. Hence, region or origin is used.

The construct of EMS comprehensiveness is based on how many environmental practices a company employs. Thus, indicators that reflect how complete and inclusive the EMS is being used. These are for instance whether the firm has an environmental policy, has implemented ISO 14001 or has implemented other 14000 series standards. Note that this variable is a dependent variable in H1, but an independent (predicting) variable in $\mathrm{H} 2$ and $\mathrm{H} 3$. Environmental performance is a second variable that is challenging to measure directly. Since all companies provide different products or services under different conditions, 'bad' or 'good' environmental performance is hard to define. Here the definition in ISO standards is used as a guideline, namely; (measurable) results of an organization's management of its environmental impact. The focus is on positive changes in environmental performance concerning its previous performance. Nevertheless, direct measurements of for instance resource usage or emissions is challenging (and not included in the dataset). For further analysis, we, therefore, proceed with indicators that from a conceptual perspective are likely to positively influence environmental performance. From all possible actions on resources and emissions, the presence of a structured programme [on resource] and has a process to reduced generation [of emission] is considered a highly likely action that results in improved environmental performance.

Financial performance was measured by the indicator revenue change. Similarly, this was calculated for companies that have submitted information about their net revenue at least three times. It is not relevant whether this was submitted in subsequent years. The coefficient for revenue change (\%/year) was calculated using the least squares method. The limitation to at least three submissions is required to prevent overfitting.

Control Variables: The main control variable used is that of the industry sector. It is expected that the nature of operations affects the usage (intensity) of resources. Secondly, certain sectors may experience other pressures, for instance from consumers, from within the industry sector, or from industry-specific regulations [34]. This control shall be used for all hypotheses.

For $\mathrm{H} 2$ and $\mathrm{H} 3$, the statistically significant determinants for $\mathrm{H} 1$ will be added as a control factor. Though a strong effect is not expected, it may be that certain company aspects have a stronger effect on the performance resulting from the EMS than on the EMS itself. For example, larger firms may have more resources dedicated to executing the EMS and as a result, reaping performance benefits. Nevertheless, from the questionnaire, the EMS comprehensiveness may appear comparable [8]. Control for industry sector results in four categories to control for, namely: agriculture, services, industry, and commerce. Table 1 presents the operationalization of variables.

Table 1. Operationalization.

\begin{tabular}{lllll}
\hline \multicolumn{1}{c}{ Variable } & Indicator(s) & Source & Format & Example \\
\hline Firm size & Employees in year X & $\begin{array}{l}\text { Council, 1978; } \\
\text { van Kranenburg } \\
\text { \& Voinea, 2017 } \\
{[48,49]}\end{array}$ & $\begin{array}{l}\text { Numerical, } \\
\text { discrete (\& log } \\
\text { normalized) }\end{array}$ & 100.3, 105.0, ... \\
& & Voinea, 2018 [17] & $\begin{array}{l}\text { Numerical, } \\
\text { discreate (\& log } \\
\text { normalized) }\end{array}$ & 100.3, 101.5, ... \\
\hline Firm experience & $\begin{array}{l}\text { Number of years in } \\
\text { (host) country }\end{array}$ & & & \\
\hline
\end{tabular}


Table 1. Cont.

\begin{tabular}{|c|c|c|c|c|}
\hline Variable & Indicator(s) & Source & Format & Example \\
\hline EMS age & $\begin{array}{l}\text { Years of business with } \\
\text { EMS in place }\end{array}$ & $\begin{array}{l}\text { Melnyk \& } \\
\text { Calantone., } 2003 \\
{[33]}\end{array}$ & $\begin{array}{l}\text { Categorical, } \\
\text { ordinal }\end{array}$ & $0-2,5-10,>10, \ldots$ \\
\hline Globalization & Region of origin & $\begin{array}{l}\text { Sharfman \& } \\
\text { Society., 2004; } \\
\text { Voinea, } 2018 \\
{[16,17]}\end{array}$ & $\begin{array}{l}\text { Categorical, } \\
\text { nominal }\end{array}$ & $\begin{array}{l}\text { Brazil, Europe, } \\
\ldots\end{array}$ \\
\hline $\begin{array}{l}\text { EMS } \\
\text { comprehensiveness }\end{array}$ & $\begin{array}{l}\text { The company has an } \\
\text { environmental policy + } \\
\text { implementation of ISO } \\
14001+\text { number of ISO } \\
14000 \text { series standards } \\
\text { implemented }\end{array}$ & $\begin{array}{l}\text { Darnall \& } \\
\text { Sadorsky, 2008; } \\
\text { Phan \& Baird, } \\
2015 \\
{[9,19]}\end{array}$ & $\begin{array}{l}\text { Categorical, } \\
\text { ordinal }\end{array}$ & $0,1,2, \ldots$ \\
\hline $\begin{array}{l}\text { Environmental } \\
\text { performance }\end{array}$ & $\begin{array}{l}\text { Presence of structured } \\
\text { programme to address } \\
\text { resources and emissions }\end{array}$ & $\begin{array}{l}\text { Nawrocka \& } \\
\text { Parker,2009; } \\
\text { Tung, Baird, \& } \\
\text { Schoch, } 2014 \\
{[4,50]}\end{array}$ & $\begin{array}{l}\text { Numerical, } \\
\text { interval }\end{array}$ & $10 \%, 80 \%, \ldots$ \\
\hline $\begin{array}{l}\text { Financial } \\
\text { performance }\end{array}$ & Revenue change & $\begin{array}{l}\text { Darnall \& } \\
\text { Sadorsky, 2008; } \\
\text { Melnyk \& } \\
\text { Calantone., } 2003 \\
{[19,33]}\end{array}$ & $\begin{array}{l}\text { Numerical, } \\
\text { interval }\end{array}$ & $4 \%,-19 \%, \ldots$ \\
\hline Control & Industry sector (control) & Voinea, 2017 [49] & $\begin{array}{l}\text { Categorical, } \\
\text { nominal }\end{array}$ & $\begin{array}{l}\text { Agriculture, } \\
\text { services, ... }\end{array}$ \\
\hline
\end{tabular}

\subsection{Data and Sample}

The data has been obtained from Análise Editorial by sending a questionnaire survey to the companies [51]. This was done bi-annually and the results for years 2010, 2012, 2014, and 2016 are used in this study. The data was combined (labelled to year), and where questions were changed over time the data was not used. Over the eight year period, 2395 questionnaires were obtained with a stable return rate of around 600 per year. Though roughly halve are companies that only submitted once, about 600 companies have multiple submissions over-time and would thus allow for change over time. A total of 148 companies have submitted the questionnaires four times (over the complete 8 year period).

\subsection{Data Preparation}

The dataset is created by combining all four bi-annual datasets. The number of indicators is reduced in order to create one measure per variable as described in Section 3.1. Research context: Environmental research, management and performance in Brazil

Compared to countries with a comparable GDP, Brazil has a relatively low energy usage per capita and a strong environmental regulatory regime [41]. Of all BRICS countries, China, India, and Brazil have the most sustainable focus on development. Possibly due to that, sufficient research on environmental management can be found for those countries, as opposed to Russia and South-Africa [42].

As of $2007,40 \%$ of the companies in Brazil had implemented a certified EMS [43]. The primary incentive and outcome of EMS is eco-efficiency. Here, on the proposed scale from reactive to preventive to proactive, Brazil can be considered preventive [44]. This means that companies are doing more than the minimum required by legislation (which is considered simply 'reactive') and are looking for options to reduce resource usage, hence eco-efficiency. They cannot be regarded as proactive, which 
would include active innovations towards more environmentally friendly processes and products with environmental-friendliness as the prime motivator [45].

A self-reflective survey study yielded a perceived positive effect on environmental performance (i.e., energy and waste reduction as well as incident reduction), and a positive effect on business, such as being more attractive to investors [43,45]. This was, however, not a quantitative study. Quantitative analysis may be performed by using disclosed information on company websites. The completeness of such information varies a lot per sector, with mainly mining, paper, and energy companies disclosing conclusive information [46].

Section 3.2. Operationalization of variables. Thus, where more than one indicator proves necessary, the indicators are combined into a composite measure. The overview is provided in Table 2. The number of employees, number of years in (host) country, years of business with EMS in place, a region of origin, revenue change, and industry sector could directly be obtained from the dataset. EMS comprehensiveness and environmental performance make use of composites. EMS comprehensiveness is measured using multiple indicators: Company has an environmental policy; Company has implemented ISO 14001; Company has implemented other ISO 14000 series standards. However, using Chi-square tests it was observed that all indicators are significantly correlated and thus resulted in high collinearity. This is likely to cause model issues when jointly integrated into a model later and thus the number of indicators was reduced. From three indicators a composite scale was constructed. The result is an ordinal combination that represents different levels of EMS comprehensiveness and is provided in Table 2. The resulting scale ranges from no EMS (0) to high EMS comprehensiveness (4).

Table 2. Scale construct for EMS comprehensiveness.

\begin{tabular}{|c|c|}
\hline Dummy Variable & EMS Comprehensiveness \\
\hline 0 & No environmental policy \\
\hline 1 & Environmental policy \\
\hline 2 & $\begin{array}{l}\text { Environmental policy }+ \text { ISO } 14001 \text { implemented OR } \\
\text { Environmental policy }+1^{*} \text { other ISO } 14000 \text { standard }\end{array}$ \\
\hline 3 & $\begin{array}{l}\text { Environmental policy }+ \text { ISO } 14001 \text { implemented }+1^{*} \text { other ISO } 14000 \text { standard OR } \\
\text { Environmental policy }+>1^{*} \text { other ISO } 14000 \text { standard }\end{array}$ \\
\hline 4 & Environmental policy + ISO 14001 implemented $+>1^{*}$ other ISO 14000 standard \\
\hline
\end{tabular}

Environmental performance makes use of multiple indicators. For the resources and emissions: Water; Electricity; Fuel; Wood and coal; Minerals; Solid waste; Effluents. The combined measure is a calculated numerical value based on how many structured programmes are in place for the resources and emissions of that company. Where a resource or emission is not relevant (for instance coal usage for a hospital) the value is compensated. The scale is calculated according to equation bellow:

$$
\text { Environmental performance }=100 \% \times \frac{\text { number of } \text { (structured) programmes in place }}{\text { number of relevant resources and emmisions }}
$$

The formula for the calculation of environmental performance: A scale from $0-100 \%$ is calculating the number of structured programmes to address resources and emissions divided by the number of relevant resources and emissions for that company. 


\section{Results}

First, we elaborate on the data content that has obtained to perform the analysis, including data shortcomings. Then, the results of statistical testing as performed to test the individual hypotheses will be presented. The goal here is also to reduce the large set of indicators into a limited set of statistically significant indicators.

\subsection{Descriptive Statistics}

Table 3 shows the descriptive statistics of the variables. According to size, firms range from five employees up to companies with 152.000 employees. This is thus a representation from small to large companies in the broadest sense. Normalization with the logarithm resulted in a comprehensible range (from 0.7 to 5.18). Moreover, visual inspection, skewness, and kurtosis indicate normality can be assumed.

Table 3. Descriptive statistics.

\begin{tabular}{lllllllll}
\hline \multicolumn{1}{c}{ Variable } & $\mathbf{N}$ & Mean & Median & Min & Max & SD & Skewness & Kurtosis \\
\hline Firm size (normalized) & 2012 & 3.18 & 3.19 & 0.70 & 5.18 & 0.66 & -0.16 & 0.56 \\
\hline Firm size * & 2012 & 4655 & 1559 & 5 & 152000 & n.a. & n.a. & n.a. \\
\hline $\begin{array}{l}\text { Firm experience } \\
\text { (normalized) }\end{array}$ & 407 & 1.64 & 1.68 & 0.60 & 2.55 & 0.31 & -0.37 & 0.12 \\
\hline $\begin{array}{l}\text { Firm experience * } \\
\text { Environmental }\end{array}$ & 407 & 55 & 48 & 4 & 353 & n.a. & n.a. & n.a. \\
\hline $\begin{array}{l}\text { performance } \\
\text { Financial performance }\end{array}$ & 423 & 48.28 & 40.00 & 0.00 & 100.00 & 32.33 & 0.35 & -0.61 \\
\hline
\end{tabular}

Firm size, firm experience (years), EMS comprehensiveness (ordinal categories 0-4), environmental performance (scale $0-100 \%$ ) and financial performance (\% net revenue change per year). For firm size both the normalized and original values are reported. * For analysis, only the normalized values are used.

Firm experience ranged from just four years up to three and a half centuries. This broad range has therefore also been normalized, which results in a population where normality can be assumed based on skewness and kurtosis values. However, visual inspection of a histogram indicates the sample may contain two distributions; one that peaks around 20 years and one that peaks around 45-50 years. Considering the date of the questionnaires, this corresponds to 1990-1995 and the 60s respectively.

Experience with the EMS shows an unbalanced sample. The reason is that 0 years of experience are companies without EMS. At 55.9\% the large majority falls in this category. The second largest group has $5-10$ years of experience $(20.5 \%)$, then $>10$ years $(11.3 \%)$, then $2-5$ years $(8.2 \%)$, and at last $0-2$ years $(4.0 \%)$. Note that categories have no equal spacing; some contain a group of five years (5-10) while others only contain two years (0-2).

The constructed scale for environmental shows a mean value of $48 \%$, properly centered in the tolerable range (0-100\%). Moreover, the standard deviation is high thus the sample makes use of the full potential of the scale.

On average, the companies experienced an annual net revenue growth of $+3.9 \%$. The sample histogram is provided in Figure 1. However, the range shows large differences ranging from $-24.5 \%$ to $+30.3 \%$. The large variance $(9.3 \%)$ also indicates the distribution is broad and in this sample, $30 \%$ of the companies experienced a decline in net revenue and thus negative financial performance. 


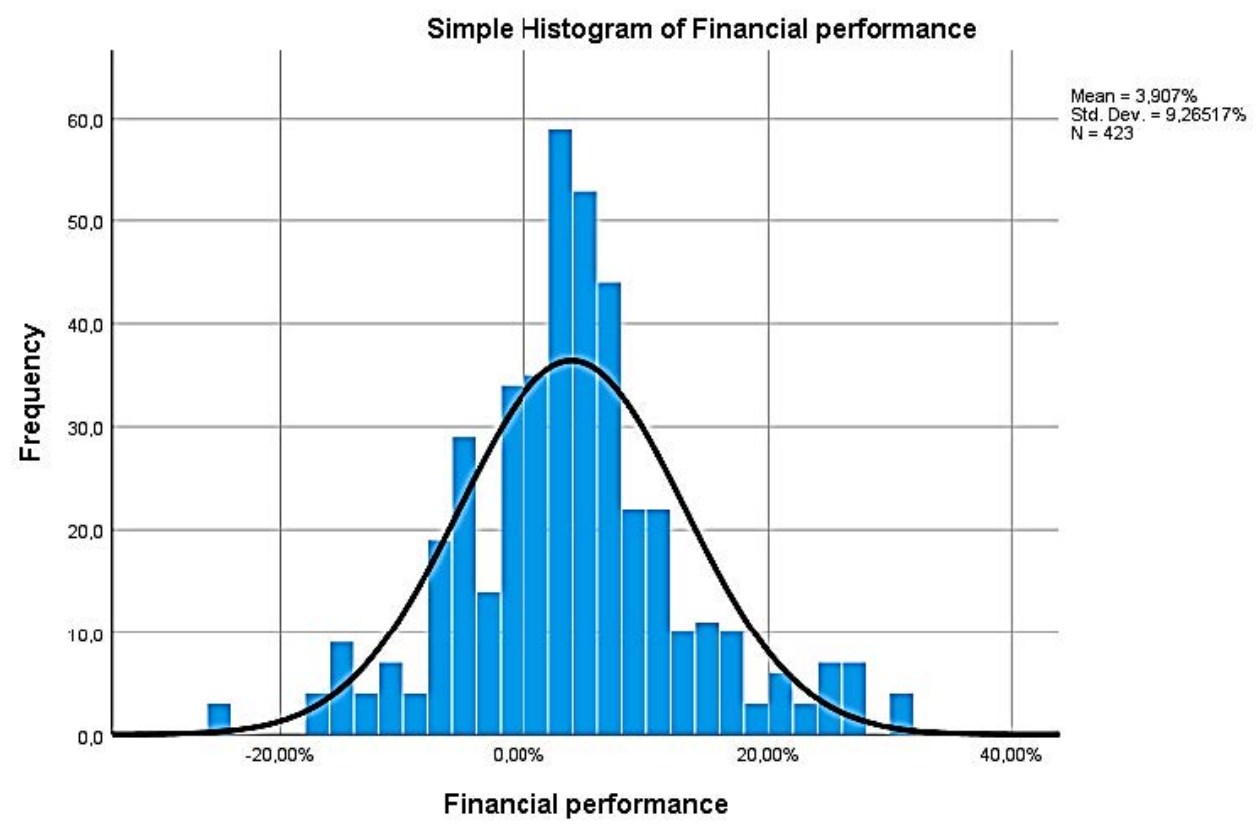

Figure 1. Sample histogram of the financial performance.

The constructed ordinal categories for EMS comprehensiveness are coded from 0-4, with 0 worst category and 4 highest score (and undefined distance between categories). The mean is 2.05 and median 2. The sample distribution is thus properly centered on the constructed scale. The variance is high and balanced; all categories are equally filled and contain roughly $20 \%$ of the samples.

Figure 1 presents the histogram of the financial performance $(\%$ change in net revenue per year). On average, a growth of $+3.9 \%$ occurred. The large standard deviation indicates a high variance in financial performance exists with $30 \%$ of the companies experiencing a net revenue decline.

Further, regarding the sector variable, industry companies have a much higher representation (at $49.1 \%)$, then services $(33.1 \%)$, while the minority sector is commerce $(5.9 \%)$ and agriculture $(11.8 \%)$.

\subsection{Cross Tabulations}

For hypothesis 2, we analyse the dataset by tabulating the different EMS comprehensiveness levels characteristics split per industry sector. This can be seen in Table 4. Clear differences can be observed. For industry companies, most companies have the highest EMS comprehensiveness score, and the large majority of companies have an above average score. For the other sectors the opposite is true. The different sectors have an apparent different distribution. The overall average value was 2.05. For industry companies, the majority has an above average EMS comprehensiveness, while it is below average for agriculture, commerce, and services.

Table 4. EMS comprehensiveness across industry sectors.

\begin{tabular}{llllll}
\hline \multicolumn{7}{c}{ EMS Comprehensiveness } \\
\hline Industry Sector & $\mathbf{0}$ & $\mathbf{1}$ & $\mathbf{2}$ & $\mathbf{3}$ & $\mathbf{4}$ \\
\hline Agriculture & $27 \%$ & $22 \%$ & $18 \%$ & $25 \%$ & $8 \%$ \\
\hline Commerce & $25 \%$ & $27 \%$ & $28 \%$ & $16 \%$ & $4 \%$ \\
\hline Industry & $11 \%$ & $14 \%$ & $26 \%$ & $20 \%$ & $29 \%$ \\
\hline Services & $20 \%$ & $31 \%$ & $16 \%$ & $16 \%$ & $16 \%$ \\
\hline
\end{tabular}

For hypothesis 2, the data was analysed by tabulating the environmental performance characteristics split to the different EMS comprehensiveness levels. As a control, this is also performed 
for the industry sector. The results can be observed in Table 5. The observation results in the assumption that statistical modelling may find a statistically significant effect of EMS comprehensiveness on environmental performance. There is a clear difference in mean values at the different EMS comprehensiveness levels. The same is true for industry sector. Industry shows a higher environmental performance, commerce \& services an average performance and the lowest performance for agriculture.

Table 5. Analysis of the different sub-groups of environmental performance for different levels of EMS comprehensiveness (top) and different industry sectors (bottom).

\begin{tabular}{llllllll}
\hline Environmental Performance & Mean & Median & Min & Max & SD & Skewness & Kurtosis \\
\hline EMS comprehensiveness & & & & & & & \\
\hline 0 & $37.5 \%$ & $33.0 \%$ & $0.0 \%$ & $100.0 \%$ & $31.1 \%$ & 0.46 & -0.93 \\
\hline 1 & $37.7 \%$ & $33.0 \%$ & $0.0 \%$ & $100.0 \%$ & $29.8 \%$ & 0.46 & 0.82 \\
\hline 2 & $50.5 \%$ & $50.0 \%$ & $0.0 \%$ & $100.0 \%$ & $31.8 \%$ & -0.01 & -1.16 \\
\hline 3 & $54.2 \%$ & $57.0 \%$ & $0.0 \%$ & $100.0 \%$ & $32.6 \%$ & -0.08 & -1.25 \\
\hline 4 & $60.1 \%$ & $60.0 \%$ & $0.0 \%$ & $100.0 \%$ & $30.2 \%$ & -0.21 & -1.11 \\
\hline Industry sector & & & & & & & -1.11 \\
\hline Industry & $58.7 \%$ & $60.0 \%$ & $0.0 \%$ & $100.0 \%$ & $30.8 \%$ & -0.25 & -0.68 \\
\hline Commerce & $38.2 \%$ & $33.0 \%$ & $0.0 \%$ & $100.0 \%$ & $31.2 \%$ & 0.59 & -1.11 \\
\hline Services & $41.1 \%$ & $40.0 \%$ & $0.0 \%$ & $100.0 \%$ & $31.4 \%$ & 0.28 & 0.49 \\
\hline Agriculture & $30.2 \%$ & $20.0 \%$ & $0.0 \%$ & $100.0 \%$ & $26.1 \%$ & 0.99 & \\
\hline
\end{tabular}

Similarly, as for hypothesis 2, comparable tabulations are created for hypothesis 3 . Here the dataset has been analysed by tabulating the environmental performance characteristics split to the different EMS comprehensiveness levels. As a control, this is also performed for the industry sector. The results can be observed in Table 6. The observation results in the assumption that statistical modelling may find a statistically significant effect of EMS comprehensiveness on financial performance. There is a clear difference in mean values at some different EMS comprehensiveness levels. Here, it seems that the lowest and highest EMS comprehensiveness results in lower financial performance. For the industry sector, the effects look minor.

Table 6. Analysis of the different sub-groups of financial performance for different levels of EMS comprehensiveness (top) and different industry sectors (bottom).

\begin{tabular}{llllllll}
\hline \multicolumn{1}{c}{ Financial Performance } & Mean & Median & Min & Max & SD & Skewness & Kurtosis \\
\hline EMS comprehensiveness & & & & & & & \\
\hline 0 & $2.8 \%$ & $4.3 \%$ & $-24.5 \%$ & $16.5 \%$ & $8.7 \%$ & -1.02 & 1.75 \\
\hline 1 & $4.8 \%$ & $4.7 \%$ & $-24.5 \%$ & $27.6 \%$ & $10.0 \%$ & 0.15 & 0.69 \\
\hline 2 & $4.6 \%$ & $4.5 \%$ & $-17.6 \%$ & $27.6 \%$ & $8.1 \%$ & 0.31 & 1.93 \\
\hline 3 & $4.6 \%$ & $4.0 \%$ & $-15.0 \%$ & $30.3 \%$ & $9.2 \%$ & 0.74 & 1.34 \\
\hline 4 & $2.7 \%$ & $2.7 \%$ & $-17.6 \%$ & $27.6 \%$ & $9.7 \%$ & 0.53 & 0.31 \\
\hline Industry sector & & & & & & & \\
\hline Industry & $3.0 \%$ & $3.0 \%$ & $-24.5 \%$ & $30.3 \%$ & $9.6 \%$ & 0.06 & 1.07 \\
\hline Commerce & $6.0 \%$ & $4.6 \%$ & $-8.9 \%$ & $26.8 \%$ & $12.6 \%$ & 0.51 & -0.67 \\
\hline Services & $4.4 \%$ & $3.7 \%$ & $-15.3 \%$ & $30.3 \%$ & $8.4 \%$ & 0.37 & 1.29 \\
\hline Agriculture & $4.9 \%$ & $5.4 \%$ & $-10.2 \%$ & $27.6 \%$ & $9.1 \%$ & 0.58 & 0.43 \\
\hline
\end{tabular}




\subsection{Hypothesis Testing}

The first model contains all predicting variables. The ordinal regression model shows an overall statistical significance (model fitting) $(\chi 2(1)=199.895, \mathrm{p}=0.000)$. The data can explain a large part of the variance in EMS comprehensiveness (Nagelkerke $R^{2} 43.0 \%$ ). Goodness-of-fit shows proper results, where Pearson's is proper goodness $(\chi 2(1)=1442.773, \mathrm{p}=0.811)$ and Deviance shows proper goodness $\left(G^{2}=987.173, p=1.000\right)$. Parameter estimates show that a high (negative) effect with the highest statistical significance on the EMS comprehensiveness is caused by EMS age $=0$ years of experience. This is an obvious result as no experience means no EMS thus the lowest score for EMS comprehensiveness.

The test of parallel lines indicates odds proportionality cannot be assumed $(\chi 2(1)=177.455$, $p=0.000$ ). A general model may thus actually provide an improved fit. However, the odds proportionality often fails under the parallel lines test, especially with many samples and a continuous predictor (ReStore, n.d.). Here, two continuous predictors are included in the model, namely firm experience and firm size.

The second model iteration removes EMS age from the model because of the prementioned reasons. The ordinal regression model shows an overall statistical significance (model fitting) $(\chi 2(1)=50.422$, $p=0.000)$. The data is able to explain a smaller part of the variance in EMS comprehensiveness (Nagelkerke $\mathrm{R}^{2} 13.1 \%$ ), but goodness-of-fit still shows proper results for Pearson's $(\chi 2(1)=1560.622$, $p=0.116)$ and Deviance $\left(G^{2}=1136.646, p=1.000\right)$. The only variable that is statistically significant is firm size. A tenfold increase in the number of employees results in about 0.35 increase in the log odds of a higher EMS comprehensiveness level $(B=0.366, p=0.024)$. The test of parallel lines indicates odds proportionality cannot be assumed $(\chi 2(1)=63.406, \mathrm{p}=0.000)$.

In a third iteration, the globalization and firm experience variables were removed. The reason is that many samples are excluded because data is missing for those variables. With firm size and control for the sector, more samples can be included in the model $(n=2012)$. The ordinal regression model shows an overall statistical significance (model fitting) $(\chi 2(1)=164.216, p=0.000)$. As expected, the data can explain an even smaller part of the variance in EMS comprehensiveness (Nagelkerke $R^{2} 8.2 \%$ ) and goodness-of-fit shows proper results where Pearson's goodness is $(\chi 2(1)=5460.640, p=0.253)$ and Deviance $\left(G^{2}=4590.841, p=1.000\right)$. The variable that is statistically significant remains firm size. A tenfold increase in several employees results in about 0.33 increase in the log odds of a higher EMS comprehensiveness level $(B=0.327, p=0.000)$. Thus, on a higher sample size model iteration, two is confirmed. Furthermore, the sector industry (w.r.t. baseline services) results in statistically significant higher odd of EMS comprehensiveness $(B=0.881, p=0.000)$. The test of parallel lines indicates odds proportionality cannot be assumed $(\chi 2(1)=82.253, \mathrm{p}=0.000)$.

Hypothesis 1a (Firm size positively relates to the comprehensiveness of the EMS, thus the larger the firm, the more comprehensive its' EMS.) was supported by data as used in this research study. The ordinal regression models show a higher EMS comprehensiveness for companies that are larger in terms of employee count. More precisely, a tenfold increase in the number of employees on average results in a factor $\mathrm{e}^{0.366}=1.44$ increase in odds of having a higher EMS comprehensiveness score $(\mathrm{B}=0.366$, $\mathrm{p}=0.024)$.

Hypothesis $1 \mathrm{~b}$ (Firm experience is positively related to the EMS comprehensiveness and thus older firms have a higher environmental management performance.) was not supported by data as used in this research study. The ordinal regression models show a lower EMS comprehensiveness for companies that have a longer experience. However, the resulting relation has no statistical significance.

Hypothesis 1c (EMS age is positively related to the EMS comprehensiveness and thus firms who have implemented an EMS for a longer period already have a higher environmental management performance.) was not supported by data as used in this research study. The ordinal regression models show no logical trend or response for EMS age. Moreover, the results are not statistically significant.

Hypothesis 1d (The degree of globalization positively influences the comprehensiveness of EMS, thus the higher the degree of globalization of the firm, the more comprehensive its' EMS.) was not supported by data as 
used in this research study. The ordinal regression models show a lower EMS comprehensiveness for companies that have their roots in Brazil and North America and a higher EMS comprehensiveness for companies with roots in Europe, South America, and Africa. However, the resulting relations have no statistical significance.

Hypothesis 2 (The more comprehensive the EMS, the larger the improvements in environmental operational performance.) was supported by data as used in this research study. Tukey's HSD shows that the cluster with lowest environmental performance, meaning performing actions for only $37 \%$ of the possible resources \& emissions, is EMS comprehensiveness value 0 and 1 . This corresponds to companies that have either no EMS at all or only an environmental policy. EMS comprehensiveness value 2 and 3 show improved environmental performance with about $52 \%$ off the possible actions. These are companies that have an environmental policy but that also implemented ISO 14001 and/or one or more other ISO standards from the 14000 series. The highest environmental performers with on average $60 \%$ of the possible actions have an environmental policy, implemented ISO14001, and more than one other ISO standard of the 14000 series.

Furthermore, firm size positively influences environmental performance. A tenfold increase in the number of employees is estimated to result in an $8 \%$ increase in environmental performance $(\mathrm{B}=7.86, \mathrm{p}=0.000)$. Also, companies from commerce and services show comparable environmental performance. Agriculture shows an on average $13 \%$ lower environmental performance $(B=-13.112$, $p=0.000)$ and industry a $15 \%$ higher environmental performance $(B=14.779, p=0.000)$. This results in three clusters with agriculture having the lowest environmental performance (estimated at $30 \%$ ), then commerce \& services (estimated at $40 \%$ ), and industry the highest performance (estimated at $59 \%$ ).

Hypothesis $3 \mathrm{a}$ (The more comprehensive the EMS, the larger the improvements in financial performance.) This hypothesis was partially supported by data as used in this research study. The model outcome suggests that a more comprehensive EMS results in a higher financial performance up to a certain level, after which financial performance is greatly reduced.

EMS comprehensiveness for companies in a particular sector results in significant differences for their expected financial performance as follows:

For the industry sectors, companies with EMS comprehensiveness $=0 \& 1$, the financial performance is much lower $(\mathrm{B}=-10.220, \mathrm{p}=0.006 \& \mathrm{~B}=-7.355, \mathrm{p}=0.023$ respectively).

For industry companies with EMS comprehensiveness $=3$, the financial performance is much lower $(\mathrm{B}=-8.060, \mathrm{p}=0.011)$.

For commerce companies with EMS comprehensiveness $=1$, the financial performance is much higher $(\mathrm{B}=17.594, \mathrm{p}=0.011)$.

For agriculture companies with average EMS comprehensiveness (3), the financial performance is much lower $(\mathrm{B}=-12.567, \mathrm{p}=0.013)$.

Moreover, the industry sector plays an important explanatory role in the model, resulting in large differences in financial performance. For instance, for the industry sector, the financial performance does not reduce with high EMS comprehensiveness and for commerce, the best financial performance was found to be companies with a low EMS comprehensiveness.

Hypothesis $3 \mathrm{~b}$ (The larger the improvements in environmental performance, the larger the improvements in financial performance.) was not supported by data as used in this research study. The model shows that higher environmental performance results in decreased financial performance.

However, when the industry sector is included in the model, the statistical significance fades out. This suggests that the differences in financial performance vary significantly per industry sector or (as found in $\mathrm{H} 2$ ) that the environmental performance varies as well significantly per industry sector.

\section{Discussion}

Based on our result some interesting observations can be made. Firstly, with increasing EMS comprehensiveness the environmental performance increases. In effect, three differentiable clusters are found that range from a 37\% environmental performance score for the lowest EMS comprehensiveness 
scores up to $60 \%$ environmental performance score for the highest EMS comprehensiveness scores. Translating this back to the used indicators for these variables it tells us that a higher degree of- and more complete adaptation of policies and standards related to environmental management results in a higher number of active actions and programmes related to the reduction of resource usage and waste generation. It is clear from our result that the inclusion of EMS in organization as an integral part may enhance its environmental performance. In addition, the more an organization considers environmental programmes while planning operational tasks, the more it may achieve environmental performance. Further, it was hypothesized that a higher degree of EMS comprehensiveness results in higher environmental performance and this was thus confirmed. Also, the lowest and highest EMS comprehensiveness scores result in lower financial performance. Here, these two extremes result in a $2 \%$ lower increase in net revenue per year, or calculated relatively; an almost 50\% lower financial performance compared to the average EMS comprehensiveness scores. This relatively large difference suggests that under- or over performing with respect to environmental management and related policies results in lower financial performance. Although it is costly to implement EMSs, several researches identify that companies can gain financial benefits from the implementation of EMSs. Our results are in accordance with recommendations from [19,33]. For that purpose, firm managers must acknowledge that an integrated effort is required to mobilize both tangible and intangible resources for better sustainable business results while dealing with environmental issues. This is particularly needed when there is an appropriate time to invest in environmental projects.

Regarding environmental performance, similar to EMS comprehensiveness and financial performance, industry companies have on average the highest environmental performance as well as the lowest financial performance. Though independent variables were controlled for collinearity, it remains unclear whether environmental performance has a direct effect on financial performance or whether these are in fact industry sector characteristics. Nevertheless, a statistically significant linear negative relationship was found between environmental performance and financial performance.

Furthermore, it has been found that company size has a positive effect on the EMS comprehensiveness. Thus, companies with more employees have on average implemented more environmental management policies and standards. Experience with the EMS was not found to have an effect on the EMS comprehensiveness. Firm experience, measured in years of operation, showed a negative trend on the EMS comprehensiveness. The resulting conclusions from this research indicate that the effects on financial performance are ambiguous where;

EMS comprehensiveness has a certain optimum where financial performance is at its highest. On average, the lower financial performance is realized with extreme EMS comprehensiveness, meaning no environmental practices at all or the implementation of a very high number of environmental practices.

Environmental performance has a negative relationship with financial performance; the higher the environmental performance, the lower the financial performance. In summary, the reverse relationship can be credited to strict environmental regulations and tough disclosure practices. There is an important implication for the managers to well aware of the regulations and try to market their company as environment friendly, so they may reduce the negative consequences of environmental performance.

\section{Conclusions}

The objective of this study was to investigate the relationship between the comprehensiveness of the environmental management systems, the environmental performance and the financial performance of MNCs in emerging economies. The relationship between EMS comprehensiveness, environmental performance, and financial performance proves to be complex. First of all, it has been observed that the comprehensiveness of EMS is positively associated with environmental performance. However, this relationship varies among industry, commerce, services, and agriculture. Second, this study reports a partial relationship between the comprehensiveness of EMS and financial performance across different industry sector. The influence of the comprehensiveness of EMS on financial performance is higher 
for commerce as compared to agriculture and industry. Finally, this study determines the opposite relationship between environmental performance and financial performance. The overall negative effect of environmental performance on financial performance may indicate that the resources needed to realize an improved environmental performance does not outweigh the cost reductions resulting from eco-efficiency or improved reputation. The effect of EMS comprehensiveness on financial performance is in line with that, indicating that an above average EMS comprehensiveness results in lower financial performance, which may correspond to high environmental management and overhead costs.

From an alternative standpoint, that of positive effects on reputation due to environmental management, the same could be claimed. Having environmental management in place arguably results in higher turnover due to an improved reputation but a too comprehensive EMS may offset that by imposing costs. Nevertheless, a differentiation between EMS comprehensiveness effects on either cost reduction or reputation (direct and indirect effects [10] is not provided in this research.

\section{Literature Reflection}

The main indicator of EMS comprehensiveness was found to be firm size, as claimed previously in prior research $[8,13]$. Regarding globalization, data suggest that companies with their roots in Brazil or North America have a lower EMS comprehensiveness than companies with their roots in Europe or Asia (mainly Japan). This contributes to the theory that firms that operate globally seem to implement on a global scale their policies such that the environmental requirements of all areas are met and, in effect, this would result in a more comprehensive EMS $[15,16]$. However, this relation was not statistically significant in this research.

Another of our findings regarding a more comprehensive EMS does result in a higher frequency of environmental actions being employed, thereby confirming existing claims regarding this relationship $[2,9,26]$. Arguably, the effect of a (comprehensive) EMS and higher environmental performance on a firm's financial performance is the most debatable and interesting claim.

For the effect of a comprehensive EMS on financial performance, an optimum was observed (at an average EMS comprehensiveness). The observed 'optimum' contradicts previous research, where the outcome was that a more comprehensiveness EMS results in higher financial performance [19]. Also, it opted that an EMS can be seen as a structuring tool to facilitate innovation [8] but this does not help in explaining the observed optimum. Other research failed to find a statistically significant relationship between EMS and financial performance. This could be due to the use of probit model regression, measuring the dependent financial performance as either improved or not [2] instead of the linear regressions used here.

The negative linear relationship between environmental- and financial performance makes it reasonable to claim that there is indeed a cost to environmental good-doing [2]. Through qualitative research is able to find good examples of firms that do realize both improved financial- and environmental performance [8], the opposite is statistically significant.

\section{Future Research}

Findings in this research have shown interesting insights, with some proving and others rejecting previous research. Arguably the most interesting finding has been that of an 'optimum' EMS comprehensiveness when striving for the best financial performance. Further research could focus on finding that optimum so that companies are able to balance environmental- and financial performance as desired from their stakeholders. Furthermore, differentiating financial performance to operating costs and sales income could aid in differentiation effects on either eco-efficiency or reputation due to environmental management [52].

In addition, it has been found that the sector a company operates in greatly affects the EMS comprehensiveness, environmental performance, and financial performance. It would be of great interest to conduct an explorative study on how these differences could be explained. Such research 
may be able to provide insights on what drives these differences, such as sector specific legislation, customer pressures or peer pressure.

At last, an obvious extension of this research would be to perform a comparative analysis on different markets. Not only should the focus be on the stage of economic development (such as other BRIC countries or Western markets) but also taking into a countries' stage of sustainability, such as whether they are reactive, preventive or proactive $[45,46]$.

Author Contributions: Conceptualization, C.L.V., B.-J.H.; methodology, C.L.V., B.-J.H.; software, C.L.V., B.-J.H.; validation, C.L.V.; formal analysis, C.L.V., B.-J.H.; investigation, H.B.A.H.; resources, C.L.V., C.F.; data curation, H.B.A.H.; writing-original draft preparation, C.L.V., B.-J.H.; writing-C.F., H.B.A.H.; visualization, C.F.; supervision, C.L.V., C.F.; project administration, C.L.V. All authors have read and agreed to the published version of the manuscript.

Funding: This research received no external funding.

Conflicts of Interest: The authors declare no conflict of interest.

\section{References}

1. Salim, H.K.; Padfield, R.; Hansen, S.B.; Mohamad, S.E.; Yuzir, A.; Syayuti, K.; Tham, M.H.; Papargyropoulou, E. Global trends in environmental management system and ISO14001 research. J. Clean. Prod. 2018, 170, 645-653. [CrossRef]

2. Hertin, J.; Berkhout, F.; Wagner, M.; Tyteca, D. Are EMS environmentally effective? The link between environmental management systems and environmental performance in European companies. J. Environ. Plan. Manag. 2008, 51, 259-283. [CrossRef]

3. Boiral, O.; Guillaumie, L.; Saizarbitoria, I.H.; Tene, C.V.T. Adoption and outcomes of ISO 14001: A systematic review. Int. J. Manag. Rev. 2018, 20, 411-432. [CrossRef]

4. Nawrocka, D.; Parker, T.J. Finding the connection: Environmental management systems and environmental performance. J. Clean. Prod. 2009, 17, 601-607. [CrossRef]

5. Lober, D.J. Evaluating the environmental performance of corporations. J. Manag. Issues 1996, 8, $184-205$.

6. Henri, J.F.; Journeault, M. Eco-control: The influence of management control systems on environmental and economic performance. Account. Organ. Soc. 2010, 35, 63-80. [CrossRef]

7. Kassinis, G.I.; Vafeas, N. Stakeholder pressures and environmental performance. Acad. Manag. J. 2006, 49, 145-159. [CrossRef]

8. Florida, R.; Davison, D. Gaining from green management: Environmental management systems inside and outside the factory. Calif. Manag. Rev. 2001, 43, 64-84. [CrossRef]

9. Phan, T.N.; Baird, K. The comprehensiveness of environmental management systems: The influence of institutional pressures and the impact on environmental performance. J. Environ. Manag. 2015, 160, 45-56. [CrossRef] [PubMed]

10. Feng, T.; Wang, D. The influence of environmental management systems on financial performance: A moderated-mediation analysis. J. Bus. Ethics 2016, 135, 265-278. [CrossRef]

11. Watson, K.; Klingenberg, B.; Polito, T.; Geurts, T.G. Impact of environmental management system implementation on financial performance. Manag. Environ. Qual. Int. J. 2004, 15, 622-628. [CrossRef]

12. Moneva, J.M.; Ortas, E. Corporate environmental and financial performance:a multivariate approach. Ind. Manag. Data Syst. 2010, 110, 193-210. [CrossRef]

13. Klassen, R.D.; Whybark, D.C. The impact of environmental technologies on manufacturing performance. Acad. Manag. J. 1999, 42, 599-615.

14. Dean, T.J.; Brown, R.L. Pollution regulation as a barrier to new firm entry: Initial evidence and implications for future research. Acad. Manag. J. 1995, 38, 288-303.

15. Christmann, P. Multinational companies and the natural environment: Determinants of global environmental policy. Acad. Manag. J. 2004, 47, 747-760.

16. Sharfman, M.P.; Shaft, T.M.; Tihanyi, L. A model of the global and institutional antecedents of high-level corporate environmental performance. Bus. Soc. 2004, 43, 6-36. [CrossRef]

17. Voinea, C.L.; Fratostiteanu, C. Corporate Social in Emerging Economies: Reality and Illusion; Routledge: New York, NY, USA, 2018. 
18. Rauf, F.; Voinea, C.L.; Hashmi, H.B.A.; Fratostiteanu, C. Moderating Effect of Political Embeddedness on the Relationship between Resources Base and Quality of CSR Disclosure in China. Sustainability 2020, 12, 3323. [CrossRef]

19. Darnall, N.; Henriques, I.; Sadorsky, P. Do environmental management systems improve business performance in an international setting? J. Int. Manag. 2008, 14, 364-376. [CrossRef]

20. Rondinelli, D.A.; Vastag, G. Panacea, common sense, or just a label? The value of ISO 14001 environmental management systems. Eur. Manag. J. 2000, 18, 499-510. [CrossRef]

21. Lesinski, B.C. Environmental Management System. Preventive L. Rep. 2001, 20, 3.

22. Boiral, O. Corporate greening through ISO 14001: A rational myth? Organ. Sci. 2007, 18, 127-146. [CrossRef]

23. Darnall, N.; Kim, Y. Which types of environmental management systems are related to greater environmental improvements? Public Adm. Rev. 2012, 72, 351-365. [CrossRef]

24. Hamschmidt, J.J.E.E. Economic and Ecological Impacts of Environmental Management Systems in Companies: Experiences from Switzerland; BoD-Books on Demand: Norderstedt, Germany, 2000.

25. Tourais, P.C.; Videira, N. Why, how and what do organizations achieve with the implementation of environmental management Systems?-Lessons from a comprehensive review on the eco-management and audit scheme. Sustainability 2016, 8, 283. [CrossRef]

26. Iraldo, F.; Testa, F.; Frey, M. Is an environmental management system able to influence environmental and competitive performance? The case of the eco-management and audit scheme (EMAS) in the European union. J. Clean. Prod. 2009, 17, 1444-1452. [CrossRef]

27. Arimura, T.H.; Hibiki, A.; Katayama, H. Is a voluntary approach an effective environmental policy instrument? A case for environmental management systems. J. Environ. Econ. Manag. 2008, 55, 281-295. [CrossRef]

28. Morrow, D.; Rondinelli, D.A. Adopting corporate environmental management systems: Motivations and results of ISO 14001 and EMAS certification. Eur. Manag. J. 2002, 20, 159-171. [CrossRef]

29. Davies, T.; Mazurek, J.; McCarthy, K.; Darnall, N. Industry Incentives for Environmental Improvement: Evaluation of US Federal Initiatives; Global Environmental Management Initiative: Washington, DC, USA, 1996.

30. Lindenberg, S.; Steg, L.; van den Berg, A.E.; de Groot, J.I.M. Environmental Psychology: An Introduction; Wiley-BPS Blackwell, 2012.

31. Aragón-Correa, J.A. Strategic proactivity and firm approach to the natural environment. Acad. Manag. J. 1998, 41, 556-567. [CrossRef]

32. Hillary, R. Environmental management systems and the smaller enterprise. J. Clean. Prod. 2004, 12, 561-569. [CrossRef]

33. Melnyk, S.A.; Sroufe, R.; Calantone, R.J. Assessing the impact of environmental management systems on corporate and environmental performance. J. Oper. Manag. 2003, 21, 329-351. [CrossRef]

34. Christmann, P.; Taylor, G. Globalization and the environment: Determinants of firm self-regulation in China. J. Int. Bus. Stud. 2001, 32, 439-458. [CrossRef]

35. Perotto, E.; Canziani, R.; Marchesi, R.; Butelli, P. Environmental performance, indicators and measurement uncertainty in EMS context: A case study. J. Clean. Prod. 2008, 16, 517-530. [CrossRef]

36. Trumpp, C.; Endrikat, J.; Zopf, C.; Guenther, E. Definition, conceptualization, and measurement of corporate environmental performance: A critical examination of a multidimensional construct. J. Bus. Ethics 2015, 126, 185-204. [CrossRef]

37. Xie, S.; Hayase, K. Corporate environmental performance evaluation:a measurement model and a new concept. Bus. Strategy Environ. 2007, 16, 148-168. [CrossRef]

38. Dragomir, V.D. How do we measure corporate environmental performance? A critical review. J. Clean. Prod. 2018, 196, 1124-1157. [CrossRef]

39. Anton, W.R.; Deltas, G.; Khanna, M. Incentives for environmental self-regulation and implications for environmental performance. J. Environ. Econ. Manag. 2004, 48, 632-654. [CrossRef]

40. Porter, M.E.; Der Linde, C.L.V. Toward a new conception of the environment-competitiveness relationship. J. Econ. Perspect. 1995, 9, 97-118. [CrossRef]

41. Voinea, C.L.; Logger, M.; Rauf, F.; Roijakkers, N. Drivers for Sustainable Business Models in Start-Ups: Multiple Case Studies. Sustainability 2019, 11, 6884. [CrossRef]

42. Esty, D.C.; Porter, M.E. National environmental performance: An empirical analysis of policy results and determinants. Environ. Dev. Econ. 2005, 10, 391-434. [CrossRef] 
43. Pinto, G.M.; Pedroso, B.; Moraes, J.; Pilatti, L.A.; Picinin, C.T. Environmental management practices in industries of Brazil, Russia, India, China and South Africa (BRICS) from 2011 to 2015. J. Clean. Prod. 2018, 198, 1251-1261. [CrossRef]

44. De Oliveira, O.J.; Serra, J.R.; Salgado, M.H. Does ISO 14001 work in Brazil? J. Clean. Prod. 2010, 18, 1797-1806. [CrossRef]

45. Jabbour, C.J.; Silva, E.M.; Paiva, E.L.; Santos, F.C. Environmental management in Brazil: Is it a completely competitive priority? J. Clean. Prod. 2012, 21, 11-22. [CrossRef]

46. Gavronski, I.; Ferrer, G.; Paiva, E.L. ISO 14001 certification in Brazil: Motivations and benefits. J. Clean. Prod. 2008, 16, 87-94. [CrossRef]

47. Trierweiller, A.C.; Peixe, B.C.; Tezza, R.; Bornia, A.C.; Campos, L.M. Measuring environmental management disclosure in industries in Brazil with item response theory. J. Clean. Prod. 2013, 47, 298-305. [CrossRef]

48. Directive, F.C. 78/660/EEC of 25 July 1978 based on Article 54 (3)(g) of the Treaty on the annual accounts of certain types of companies. OJ L, 222(14.08). 1978. Available online: www.academia.edu (accessed on 2 December 2019).

49. Van Kranenburg, H.; Voinea, C.L. Nonmarket strategies predictors for foreign firms. Scand. J. Manag. 2017, 33, 82-92. [CrossRef]

50. Tung, A.; Baird, K.; Schoch, H. The relationship between organisational factors and the effectiveness of environmental management. J. Environ. Manag. 2014, 144, 186-196. [CrossRef] [PubMed]

51. Editorial, A. 2016. Available online: https://analise.com/ (accessed on 3 July 2018).

52. Voinea, C.L.; Fratostiteanu, C.; Romein, B. The Influence of Governance and Ownership on CSR Practices in Romania. Eur. J. Sustain. Dev. 2019, 8, 313. [CrossRef]

(C) 2020 by the authors. Licensee MDPI, Basel, Switzerland. This article is an open access article distributed under the terms and conditions of the Creative Commons Attribution (CC BY) license (http://creativecommons.org/licenses/by/4.0/). 